\title{
Analysis of Low Voltage Bridgeless AC DC Energy Conversion
}

\author{
Harshita Bajpai ${ }^{1}$, A. K. Sharma ${ }^{2}$ \\ M. Tech. Student, Department of Electrical Engineering, Rajasthan Technical University, Kota, India ${ }^{1}$ \\ Associate Professor, Department of Electrical Engineering, Rajasthan Technical University, Kota, India ${ }^{2}$
}

\begin{abstract}
The energy source for energy harvesting micro-generators is present as ambient background. Energy harvesting micro generator provide a very small amount of power for low-energy electronic devices. This paper presents the analysis of electromagnetic resonant micro-generator for the low voltage bridgeless AC DC energy conversion. The proposed converter model uses parallel connected boost and buck-boost converters to step up and rectify the low AC voltage fed from the micro-generator output to higher DC voltage to be fed to an electronic load. The positive and negative half cycle of the AC voltage obtained by the micro-generator is processed by the boost and the buck-boost converters respectively. Detailed analysis of the boost and the buck boost converter of the proposed model are carried out to suit the specifications of the micro-generator output and the load.
\end{abstract}

Keywords: micro-generator, boost converter, low voltage, AC DC energy conversion, boost converter, MOSFET.

\section{INTRODUCTION}

All portable electronic devices are powered by batteries [24], [34]. Energy harvesting from environmental or human sources has proven to be implemented effectively in battery driven devices [7], [24]. Many types of microgenerators are used in the self-powered devices and many of them are reported in various literary works for avoided and single stage boost converters were used for harvesting energies in different forms [7]-[12], [15], [18], the stepping up of low voltages [13], [16], [18] , [35]-[37]. [20]-[22]. The electromagnetic micro-generators have the A direct method for AC DC conversion is presented in [2], highest energy density and in the presented AC DC [5] that form the basis of the proposed converter. A direct bridgeless converter, energy is extracted from an AC DC converter is used for efficient energy harvesting electromagnetic system [3], [5], [30], [44]. The from the low voltage micro generator output to voltage electromagnetic generators are spring mass damper based that can be fed to the electronic load. This converter systems where small magnitude ambient mechanical avoids the use of bride rectifiers, and directly converts the vibrations are amplified and the motion is converted to $\mathrm{AC}$ input to the required DC output. The converter utilizes electrical energy by electromagnetic coupling [3], [29]. a boost converter and a buck-boost converter that operate The micro-generator used is one such electromagnetic in parallel with each other to process the positive and the system [10], [18]. There are many micro-generators, negative half cycles of the AC input voltage.

which harvest mechanical energies from the ambient and they are currently the focus of many research groups [11][15]. The Fig. 1 shows the block diagram of an energy harvesting system.

The inertial micro-generators have different energy conversion principles and hence they can be classified into three major types that are [3], [25]:

- Electromagnetic

- Electrostatic

- Piezoelectric

In the electromagnetic micro-generator, mechanical energy is converted into electrical energy by electromagnetic coupling [30]. Just as electromagnetic generators, the micro-scale electrostatic or capacitive forces have become quite significant and several methods have been devised to generate electrical energy from capacitive sources [25]. A piezoelectric material can produce an electric potential, high voltage (low current) when it is put under strain that can be either compressing or deflecting [21], [3], [15], [18], and [29]. Conventional

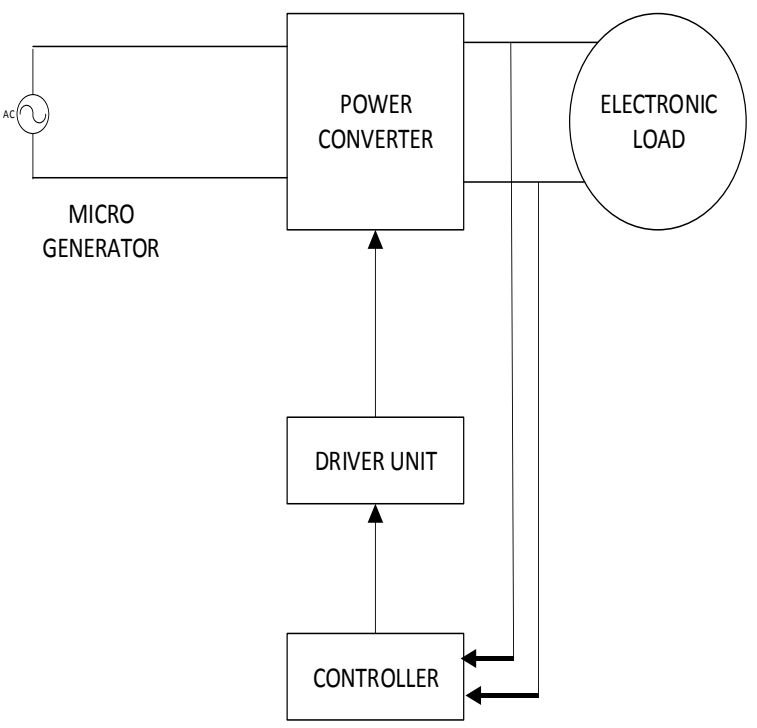

Fig 1 Block diagram for low voltage energy harvesting with power converter 
INTERNATIONAL JOURNAL OF INNOVATIVE RESEARCH IN ELECTRICAL, ELECTRONICS, INSTRUMENTATION AND CONTROL ENGINEERING

The paper is organized in IV different sections. The The voltage induced in the generator is section I gives a brief introduction of the previous literary works done in the field of low voltage energy harvesting. Section II presents the detailed analysis of the electromagnetic micro-generator. The III section describes and analyses the proposed converter topology for low voltage bridgeless AC DC energy conversion. Section IV gives the modelling, simulation and the results of the proposed converter topology. The low voltage AC from the micro-generator output is efficiently rectified and stepped up to a higher magnitude DC voltage.

\section{ANALYSIS OF ELECTROMAGNETIC MICRO- GENERATOR}

An Electromagnetic generator uses the permanent magnet and coil arrangement for damping purpose. It can also be called as the VDRG or the velocity damping resonant generator since, the damping force is opposing the proof mass integral velocity and it is best suited for sources that have high frequency and low amplitude.

The optimal damping factor $\zeta$ is given by

$$
\zeta=\frac{\mathrm{Y}_{\mathrm{o}}}{2 \mathrm{Z}_{1}}
$$

Where, $\mathrm{Y}_{\mathrm{o}}=$ source vibration amplitude

$$
\begin{aligned}
& =25 \mu \mathrm{m} \\
\mathrm{Z} & =1 \mathrm{~mm}
\end{aligned}
$$

In this case, $\zeta=0.0125$

The power extracted is hence given by:

$$
\mathrm{P}_{\mathrm{D}}^{\mathrm{opt}}=\frac{\mathrm{v}^{2}}{2 \mathrm{D}}=\frac{\left(\omega \mathrm{Z}_{\mathrm{l}}\right)^{2}\left(2 \mathrm{~m} \omega_{\mathrm{n}} \zeta\right)}{2}
$$

Where $\mathrm{v}=$ proof mass velocity

$\mathrm{D}=$ damping coefficient

$\omega_{\mathrm{n}}=$ resonating frequency, where frequency $\mathrm{f}$ in $\mathrm{Hz}$ is $322 \mathrm{~Hz}$

$$
\mathrm{m}=\text { proof mass }=0.5 \mathrm{~g}
$$

The power obtained from the above damper based system is $52 \mathrm{~mW}$.

The Fig. 2 depicts a typical inertial electromagnetic microgenerator. A key design choice to process the power circuit is the current and the corresponding voltage at which the power has to be extracted for rectification. To minimize the conduction power loss occurring in the diode in the conventional switch diode circuits to the smallest value they must work at voltage above $1 \mathrm{~V}$. Even if the synchronous rectification is carried out with a MOSFET switch, then too it must be kept in mind that the current value should be minimum and the voltage should have a sufficiently high voltage. To meet this requirement the size of the coil may exceed the available space or it may be difficult to fabricate. Also, if a large size of the coil is utilized then it may increase the number of turns which increases the self-inductance of the coil close to the square of the total number of turns and the induced voltage may increase proportionately. To counteract this, if more conductor material is added to the coil or more turns with the same area of cross section or same turns at greater area of cross section will increase the area over which the flux will be supported in the air gap between the two magnetic materials resulting in greater volume of permanent magnet.

$$
\mathrm{V}_{\mathrm{g}}=\mathrm{NBI}_{\mathrm{a}} \omega \mathrm{Z}_{\mathrm{l}}
$$

Where $I_{a}=$ active length of coil (length cutting the magnetic field during vibration)

$$
\begin{aligned}
& \mathrm{N}=\text { number of turns } \\
& \mathrm{B}=\text { maximum flux density (approx. } 1.2 \text { tesla) }
\end{aligned}
$$

For a VDRG micro engineered generator the active length can be taken as $20 \mathrm{~mm}$. This will give an induced voltage per turn to be $48 \mathrm{mV}$. Hence, if a single turn is used then the power that may be extracted will be around $48 \mathrm{mV}$ and the impedance of the turn will be very low. Now, if six turns are used instead then too the voltage will be about $300 \mathrm{mV}$, which is very low for the conventional diode rectifiers. The voltage will have to be stepped up by 10 times for use in standard electronics.

The literature indicates that often such high voltages are quite difficult to achieve even if the flux gradient, active length and operating frequency are lower. Hence, low voltage rectification and stepping up of the voltage are the basic requirements of inertial micro-generator systems. The proposed converter topology has been developed to extractenergy from electromagnetic micro-generator systems.

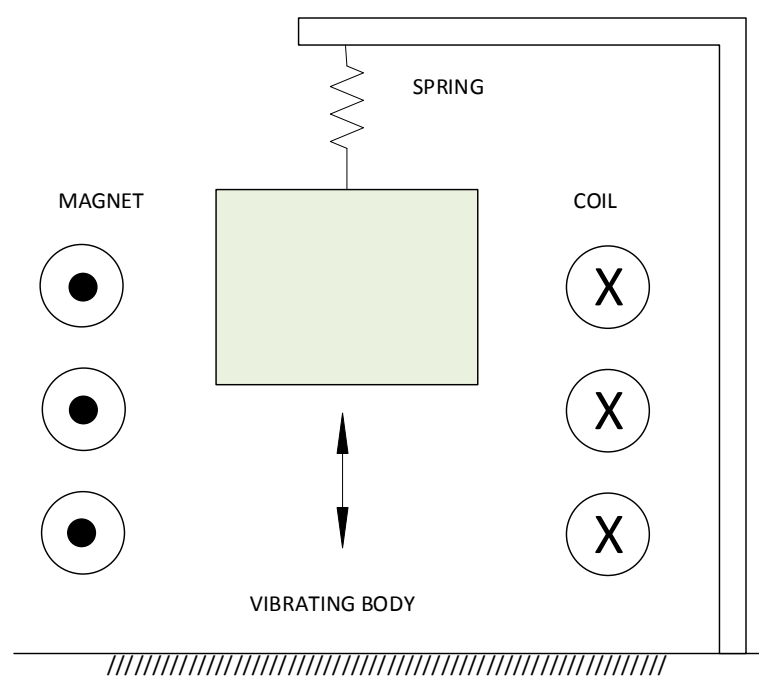

Fig 2 Schematic diagram of electromagnetic microgenerator

\section{III.PROPOSED DIRECT LOW VOLTAGE BRIDGELESS AC DC CONVERTER}

A direct AC DC converter is proposed, as shown in Fig. 3, for efficient energy harvesting from the low voltage micro generator output to voltage that can be fed to the electronic load. This converter avoids the use of bride rectifiers, and directly converts the $\mathrm{AC}$ input to the required $\mathrm{DC}$ output. The converter utilizes a boost converter and a buck-boost converter that are operating in parallel with each other to process the positive and the negative half cycles of the AC input voltage. the micro-generator output voltage is modelled in the proposed converter as an AC voltage source. The proposed circuit consisting of various elements such as inductors, MOSFET's that constitute the switches, diodes and capacitors etc. The output is 
modelled byplacing a resistive load at the output terminal. The equations for the input cycle of the converter can be There are some key points in the working of the converter. expressed as depicted in Fig. 4:

The switches S1 and S2 are realized using MOSFET's. The MOSFET's are so chosen that the forward voltage drop of their body diode is higher in value than the peak voltage of the input AC source, so that the reverse voltage applied to the switches is blocked. The diodes D1 and D2 are schottky in nature to take advantage of their very low forward voltages. The converter is designed to be implemented in the discontinuous mode of operation or DCM to reduce the switching losses and diode reverse recovery loss. The above feature also enables in the implementation of maximum energy harvesting. Also, under DCM operation, for constant duty cycle, the input current is proportional to the input voltage at every switching cycle which is beneficial for maximum energy harvesting. This study is limited to the electromagnetic micro-generators that have low output voltages $(<1 \mathrm{~V})$ for conversion of power. As the micro generator output is typically in a sinusoidal form, an AC voltage source whose voltage is taken in milli volts is taken. The circuit in Fig. 7 consisting of inductor L1, switch S1, diode D1 and capacitor $\mathrm{C}$ constitutes the boost converter, and the circuit that consists of switch S2, inductor L2, diode D2 and the capacitor constitutes the buck-boost converter to process the positive and the negative half cycles of the AC input voltage.

A. Analysis of the proposed low voltage bridgeless AC DC converter

If we plot the input current waveform of the converter together with the current waveform of the boost and buck boost converter, there are certain anomalies that will be present. Considering the input waveform of the converter, it is noted that during the positive half cycle of the input the boost inductor current $\left(i_{L 1}\right)$ and the input current $i$ are equal, but during the buck-boost converter operation, the input current $i$ and the buck-boost inductor current $\left(i_{L_{2}}\right)$ are not equal. This happens because during the buck boost converter cycle, the input current becomes zero during the period when the switch is turned OFF. Hence the energy transferred to the output by a buck-boost converter cycle is equal to the energy that is stored in the inductor, whereas, in the boost converter cycle, the energy transferred to the output exceeds the energy stored in the inductor as shown in Fig. 6. Therefore, for equal duty cycles, the input voltages and input values of the inductor are equal $(\mathrm{L} 1=$ L2). But, the total power delivered by both the converters over an input cycle of voltage are not equal. The relationship between the control and circuit parameters of the boost and the buck-boost converters pertaining to the input power and the output power is obtained in the analysis of the converter.

Considering the kth switching cycle of the boost and the buck-boost converters, where:

$\mathrm{T}_{\mathrm{s}} \quad=$ time period of the switching cycle

$\mathrm{D}_{\mathrm{b}}=$ duty cycle of the boost converter

$\mathrm{d}_{\mathrm{f}} \mathrm{T}_{\mathrm{s}}=$ boost inductor current fall time

$\mathrm{D}_{\mathrm{c}}=$ duty cycle of buck-boost converter

$\mathrm{v}_{\mathrm{i}}=$ input voltage of generator with amplitude $\mathrm{V}_{\mathrm{p}}$

$\mathrm{V}_{\mathrm{o}}=$ converter output voltage

$$
\begin{gathered}
v_{i k}=V_{p} \sin \left(\frac{2 \pi k T_{S}}{T_{i}}\right) ; \\
m_{1}=\frac{v_{i k}}{L_{1}} ; m_{2}=\frac{V_{o}-v_{i k}}{L_{1}}
\end{gathered}
$$

The switching time period of the converter $\left(T_{s}\right)$, is much smaller than the time period of the input AC voltage cycle, given by $\mathrm{T}_{\mathrm{i}}$, therefore the peak value of the inductor current $i_{P k}$ in the boost converter cycle can be written as:

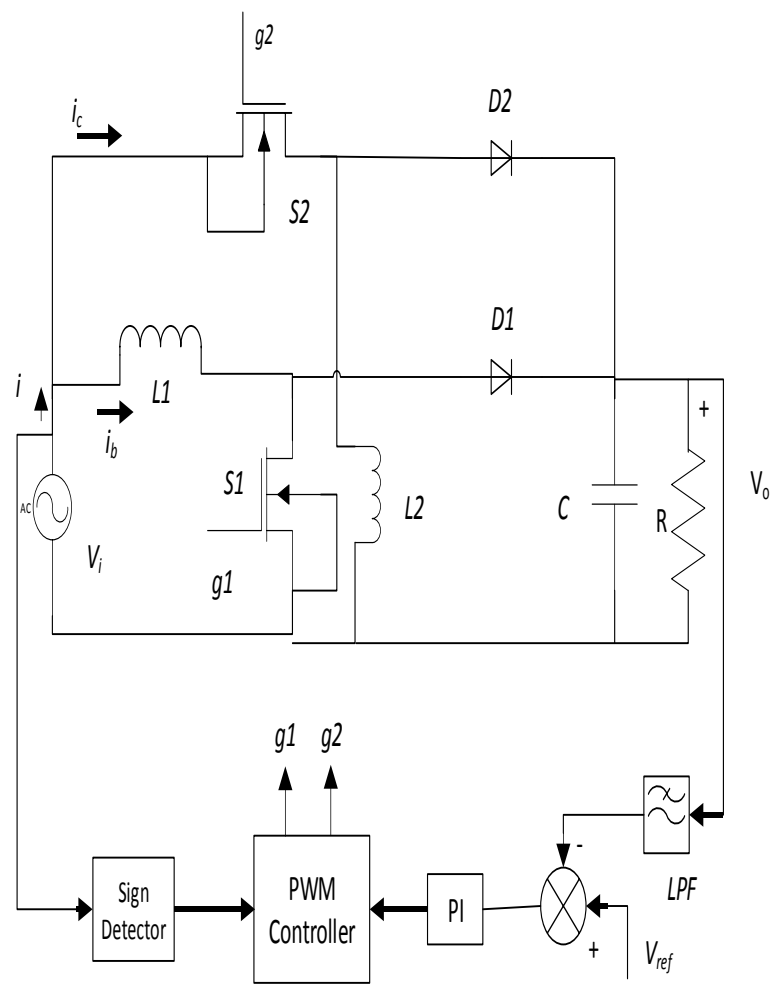

Fig 3 Proposed direct AC DC converter diagram

$$
i_{p k}=m_{1} D_{b} T_{s}=\frac{v_{i k} D_{b} T_{S}}{L_{1}}
$$

The current in the inductor starts to fall when the boost converter switch is turned OFF. The slope $\left(\mathrm{m}_{2}\right)$ of this current is determined by the voltage present across the inductor. During kth switching cycle, the voltage that is present across the inductor during current fall time can be written as $\mathrm{V}_{\mathrm{o}}-v_{i k}$. The inductor current fall time can be hence, found as:

$$
d_{f} T_{s}=\frac{i_{p k}}{m_{2}}=\frac{i_{p k} L_{1}}{V_{o}-v_{i k}}
$$

During this cycle, the total amount of energy that is transferred from the input of the boost converter is derived as:

$$
E_{k b}=\frac{v_{i k} i_{p k}\left(D_{b}-d_{f}\right) T_{S}}{2}
$$

The average power that is supplied in the switching cycle of the boost converter is:

$$
P_{i k}=\frac{E_{k}}{T_{s}}=\frac{v_{i k} i_{p k}\left(D_{b}-d_{f}\right)}{2}
$$


During the time duration or time period of one switching The duty cycle for the buck boot converter can be obtained cycle, the number of switching cycles are defined as $\mathrm{N}=$ as: $\mathrm{T}_{\mathrm{i}} / \mathrm{T}_{\mathrm{s}}$. Since the boost converter is operated for half time period of the $\mathrm{AC}$ cycle given by $\mathrm{Ti} / 2$, the average input power of the boost converter during this half time period is given as:

$$
P_{i b}=\frac{2}{N} \sum_{k=1}^{N / 2} P_{k b}=\frac{2}{N} \sum_{k=1}^{N / 2} \frac{v_{i k} i_{p k}\left(D_{b}-d_{f}\right)}{2}
$$

For large values of $\mathrm{N}$, discrete function is treated as a continuous function. Therefore, the average input power of the boost converter can be obtained if we integrate the term in the summation over the half cycle period of the input $\mathrm{AC}$ voltage. The mean value can be taken then. Hence, on the form of integration the boost converter power of the positive half cycle can be expressed as:

$$
\begin{gathered}
P_{i b}= \\
\frac{2}{T_{i}} \int_{0}^{\frac{T_{i}}{2}}\left(D_{b} T_{s} V_{p}^{2} \sin ^{2}\left(\frac{2 \pi t}{T_{i}}\right)\right) * V_{o}\left(V_{o}-V_{p} \sin \left(\frac{2 \pi \mathrm{t}}{\mathrm{T}_{\mathrm{i}}}\right)\right)^{-1} \mathrm{dt}
\end{gathered}
$$

$\mathrm{v}_{\mathrm{i}}=$ micro-generator input voltage $=\mathrm{V}_{\mathrm{p}} \sin \left(\frac{2 \pi \mathrm{t}}{\mathrm{T}}\right)$

After solving the above equation, the power for the boost converter $\mathrm{P}_{\mathrm{ib}}$ is found as:

$$
\begin{gathered}
P_{i b}=\frac{V_{p}^{2} D_{b}^{2} T_{s} \beta}{4 L_{1}} \\
\text { Where } \beta=\frac{2}{\pi} \int_{0}^{\pi} \frac{1}{1-\frac{V_{p}}{V_{o}} \sin \theta} d \theta \text { and } \Theta=\frac{2 \pi t}{T_{i}}
\end{gathered}
$$

It is duly noted from the above equations and analysis that the value of $\beta$ is constant for the fixed value of $V_{p}$ and $V_{o}$. for larger values of switching frequency of the converter, the average power is independent of the micro-generator output frequency and the output voltage. During the steady state operation, the average input power of the converter is equal to the summation of the average output power and the various losses of the converter. Hence, by defining the efficiency of the converter as $\eta$, for a load resistance $R$, the power of the input and output can be balanced as:

$$
\frac{\mathrm{V}_{\mathrm{p}}^{2} \mathrm{D}_{\mathrm{b}}^{2} \mathrm{~T}_{\mathrm{s}}}{4 \mathrm{~L}_{1}} \beta=\frac{\mathrm{V}_{\mathrm{o}}^{2}}{\mathrm{R} \eta}
$$

The boost converter duty cycle $\mathrm{D}_{\mathrm{b}}$ can be thus obtained as:

$$
\mathrm{D}_{\mathrm{b}}=\frac{2 \mathrm{~V}_{\mathrm{o}}}{\mathrm{V}_{\mathrm{p}}} \sqrt{\frac{\mathrm{L}_{1}}{\mathrm{R \eta \beta \textrm {T } _ { \mathrm { s } }}}}
$$

Now, considering the operation of the buck-boost converter, the input power is supplied only during the ON period of the switch $S_{2}$. During the OFF cycle of the switch $S_{2}$, the input current is zero, therefore for any kth switching cycle, the average power that is being supplied by the buck-boost converter can be obtained by evaluation as:

$$
\mathrm{P}_{\mathrm{kc}}=\frac{\mathrm{v}_{\mathrm{ik}} \mathrm{i}_{\mathrm{pk}} \mathrm{D}_{\mathrm{c}}}{2}
$$

The average power can be expressed in the buck-boost converter in the same way as in the boost converter. The integration form of the average power is given by:

$$
\mathrm{P}_{\mathrm{ic}}=\frac{2}{\mathrm{~T}_{\mathrm{i}}} \int_{0}^{\mathrm{T}_{\mathrm{i}} / 2} \frac{\mathrm{D}_{\mathrm{b}}^{2} \mathrm{~T}_{\mathrm{s}}}{2 \mathrm{~L}_{1}} \mathrm{~V}_{\mathrm{p}}^{2} \sin ^{2}\left(\frac{2 \pi \mathrm{t}}{\mathrm{T}_{\mathrm{i}}}\right) \mathrm{dt}=\frac{\mathrm{V}_{\mathrm{p}}^{2} \mathrm{D}_{\mathrm{b}}^{2} \mathrm{~T}_{\mathrm{s}}}{4 \mathrm{~L}_{1}}
$$

$$
\mathrm{D}_{\mathrm{c}}=\frac{2 \mathrm{~V}_{\mathrm{o}}}{\mathrm{V}_{\mathrm{p}}} \sqrt{\frac{\mathrm{L}_{2}}{\mathrm{R \eta T_{ \textrm {s } }}}}
$$

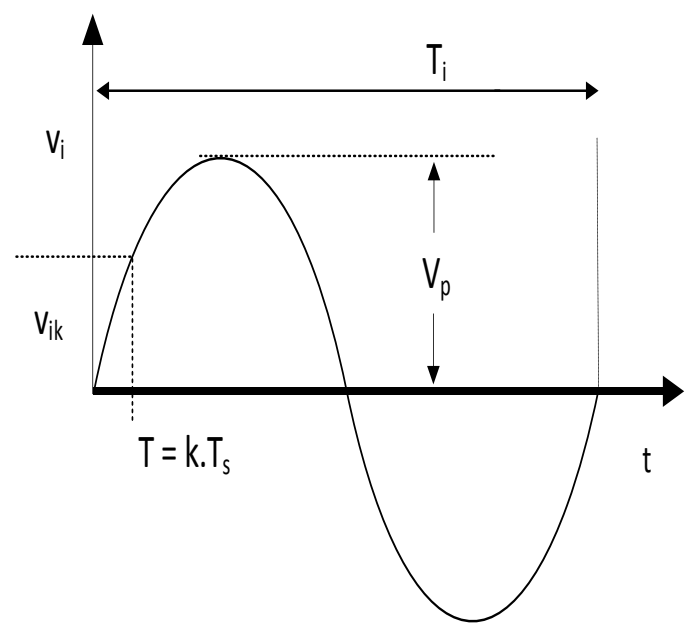

Fig 4 Input voltage during the switching cycle of the converter

The duty cycle of the boost and buck-boost converter can be related as:

$$
\frac{\mathrm{D}_{\mathrm{b}}}{\mathrm{D}_{\mathrm{c}}}=\sqrt{\frac{\mathrm{L}_{1}}{\beta \mathrm{L}_{2}}}
$$

Where $\mathrm{D}_{\mathrm{b}}=$ duty cycle of boost converter

$\mathrm{D}_{\mathrm{c}}=$ duty cycle of buck-boost converter

Based on the above equation there can be two different control methods that can be proposed for the converter so that it delivers equal average input power. The first method can be to keep the values of the inductors equal, i.e. $\mathrm{L} 1=\mathrm{L} 2$, and the control of the converters are carried out with different duty cycles. In this case the condition $D_{c}$ $=D_{b} \sqrt{ } \beta$ is satisfied and the converter operates with different duty cycles. The second method both the converters, boost and buck-boost are controlled with the same duty cycle $\left(D_{b}=D_{c}\right)$ and therefore the inductor values relate as: $L_{1}=\beta L_{2}$. The variable $\beta$ is being plotted as a function of step ratio i.e. $V_{o} / V_{p}$ in the Fig. 5. It can be deduced that for greater values of voltage step up ratio, the value of $\beta$ approaches unity.

Therefore a very important conclusion is thereby presented, that if the step up ratio is very high, then the value of $\beta$ will tend to unity and the converter can be designed with parameters with equal duty ratio and equal value of inductance. This result is very useful for the proposed converter because very low voltage is stepped up to a comparatively higher amount of output voltage.

\section{IV.SIMULATION OF THE PROPOSED LOW VOLTAGE BRIDGELESS AC DC ENERGY CONVERTER}

An electromagnetic micro-generator based on the resonating influence, producing a peak sinusiodal output voltage of $400 \mathrm{mV}$ having $100 \mathrm{~Hz}$ frequency is considered 
in this study for the proposed converter topology. The closed loop simulation is carried out based on the control schemes discussed previously. The reference output voltage $\left(\mathrm{V}_{\text {ref }}\right)$ is taken to be $3.3 \mathrm{~V}$. the energy harvesting converter is simulated to supply power to a $200 \Omega$ resistor, therefore, supplying a $55 \mathrm{~mW}$ of output power.

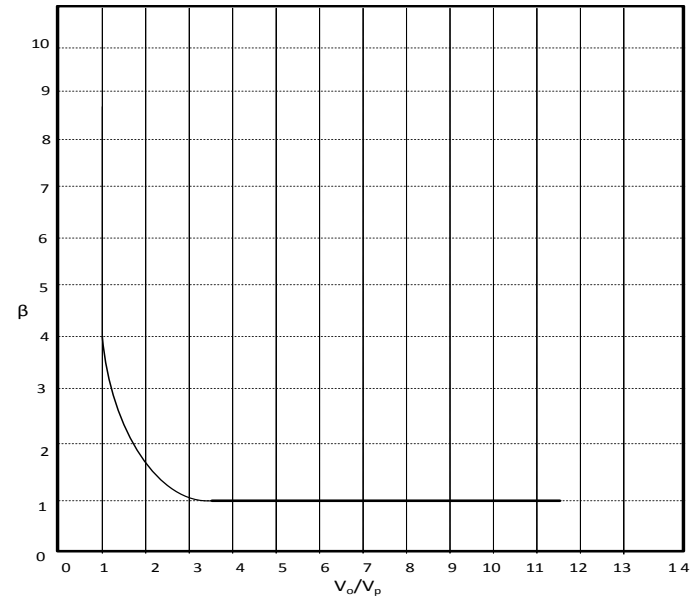

Fig 5 Plot of $\beta$ versus $\mathrm{V}_{\mathrm{o}} / \mathrm{V}_{\mathrm{p}}$

Based on the previous analysis and design guidelines discussed the converter design is carried out. MOSFETs are used for the realization of the switches $S_{1}$ and $S_{2}$. The forward voltage of the selected MOSFET body diode is about $0.8 \mathrm{~V}$, which is taken to be higher than the peak voltage at the input. This inhibits any reverse current flowing in MOSFETs. The nominal duty cycle is assumed to be 0.7 . The inductor is designed for a standard value of $4.7 \mu \mathrm{H}$ and is commercially available. Based on these design values, the frequency of switching can be approximated as $50 \mathrm{kHz}$. The dioes, $\mathrm{D}_{1}$ and $\mathrm{D}_{2}$ are chosen to be the schottky type and have a low value of forward voltage. The output capacitor value is $68 \mu \mathrm{F}$. The simulations of the converter are carried out in mathworks software. Circuit models of the selected devices and components, are used in the simulations. The various values for the circuit components of the proposed converter have been already discussed. In the simulation, the duty cycle of the boost converter $\mathrm{D}_{\mathrm{b}}$ is estimated by a PI controller.The buck- boost converter duty cycle $\mathrm{D}_{c}$ is calculated from the duty cycle estimated $D_{b}$. the input current of the boost and the buck-boost converter for load $\mathrm{R}=200 \Omega$. The total input current and the microgenerator output voltage will be shown by the simulation results. The boost converter is operated during the positive half cycle, and the buck-boost converter is operated during the negative half cycle of the micrognerator output voltage.The results are obtained in MATLAB simulink software. The output ripple is $0.14 \%$ $\mathrm{V}$, which is approximately $4.24 \%$ of the nominl output voltage. The efficiency of the converter is approximated to be $63 \%$. The duty cycle from the analysis is calculated to be equal to 0.71 . The estimated duty cycle of the converter closely matches the estimated duty cycle that was calculated analytically. The output to input peak voltage ratio is $\mathrm{V}_{\mathrm{o}} / \mathrm{V}_{\mathrm{p}}=8.25$. Furthurmore, the duty ratios of both the boost converter and the buckboost converter are found to be almost equal hence, the previous conclusions are corroborated that for higher step-up ratios the duty ratios and the inductance values for both the converters are almost equal.For a simple control structure, and less complicated circuitry, both the boost and the buck-boost converters can be controlled with same duty ratios if the voltage are high.To validate the speculations, simulations are carried out and from the resulting plots it is seen that the converter is able to produce successful results with desired output voltage and ripple. The output from the micro-generators is modelled by the $\mathrm{AC}$ voltage source in the converter circuit and the waveforms obtained are shown below in Fig. 8. The waveforms through the inductor current of the boost and the buck-boost circuit are shown in the diagram below. It is clearly depicted that during the positive half cycle of the converter current flows through the boost circuit and during the negative half cycle it flows through the buck-boost circuit. The waveform in Fig. 9 explicitly describes the process. The output of the converter is a stepped up DC wave of $3.3 \mathrm{~V}$ in magnitude. This output is sufficient to feed small scale power electronic devices.

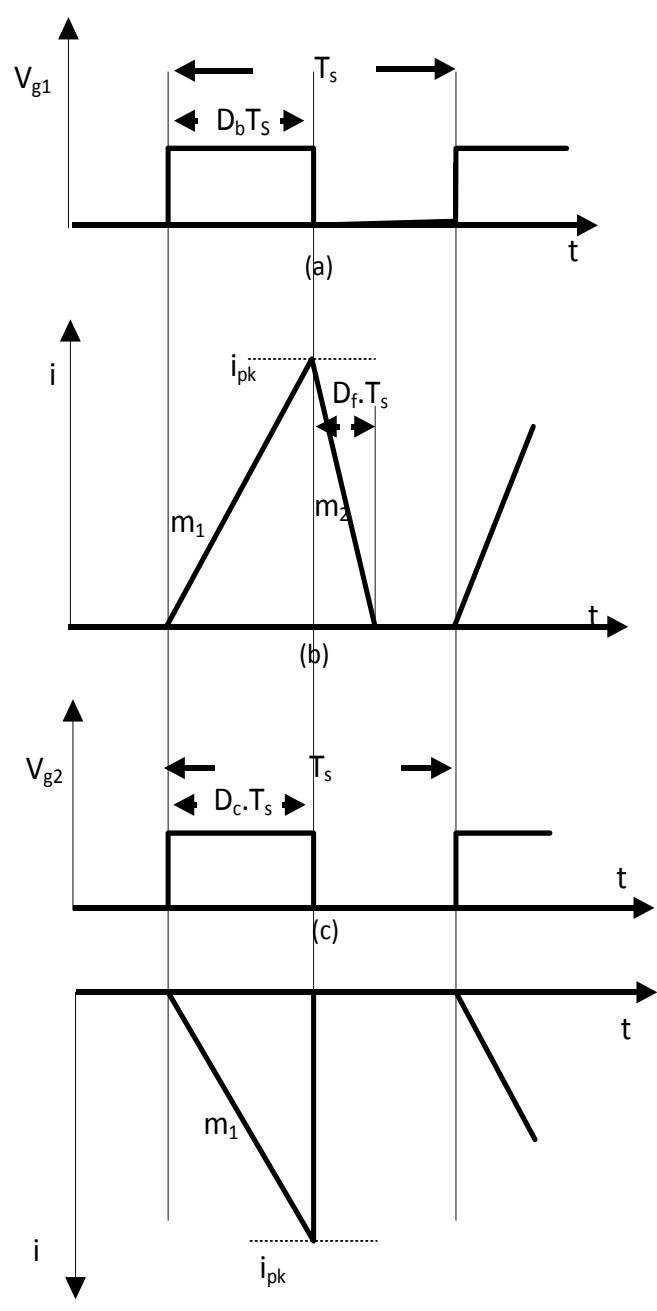

(d)

Fig 6 (a)gate signals during the boost cycle (b) Input currents during a switching cycle of boost converter waveform of the converter (c) gate signals during the buck- boost converter cycle of the converter(d) input current during the buck-boost converter cycle 
INTERNATIONAL JOURNAL OF INNOVATIVE RESEARCH IN ELECTRICAL, ELECTRONICS, INSTRUMENTATION AND CONTROL ENGINEERING Vol. 4, Issue 2, February 2016

The results obtained from the simulation of the proposed converter are hence verified by the load $\mathrm{R}=200 \Omega$. The output waveforms are shown in Fig. 10.

\section{CONCLUSION}

The electromagnetic micro-generators that form the basis of the low voltage energy harvesting technique have been analysed. A direct method for the low voltage bridgeless AC DC energy conversion has been proposed by paralleling a boost converter with a buck-boost converter. The positive and negative half cycles of the microgenerator output voltage are processed by the boost and the buck-boost converter respectively. The negative gain present in the buck-boost converter has been used to step up the negative half voltage cycle of the converter to a positive DC voltage.

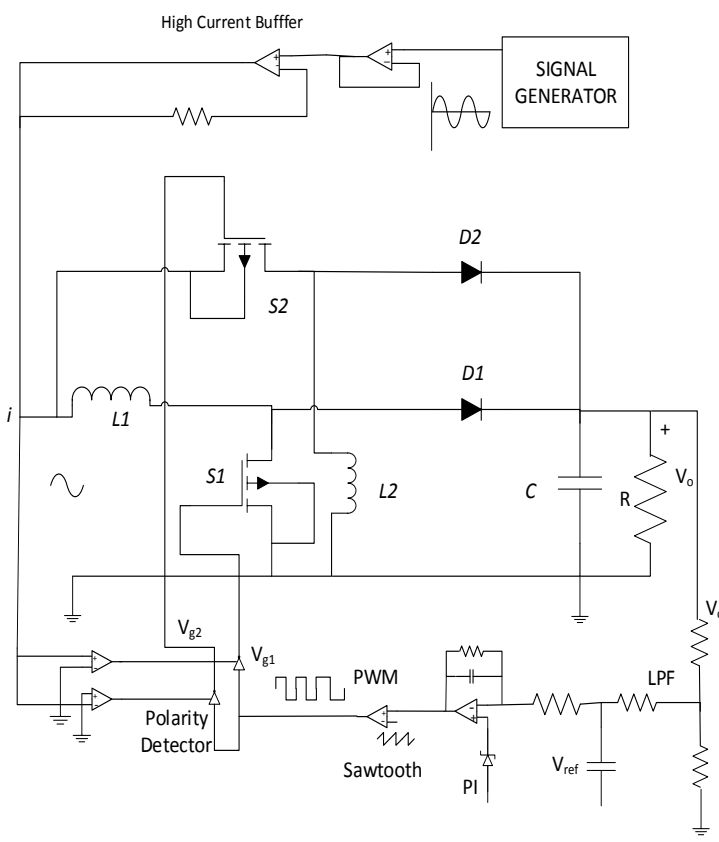

Fig 7 Circuit diagram of energy harvesting converter
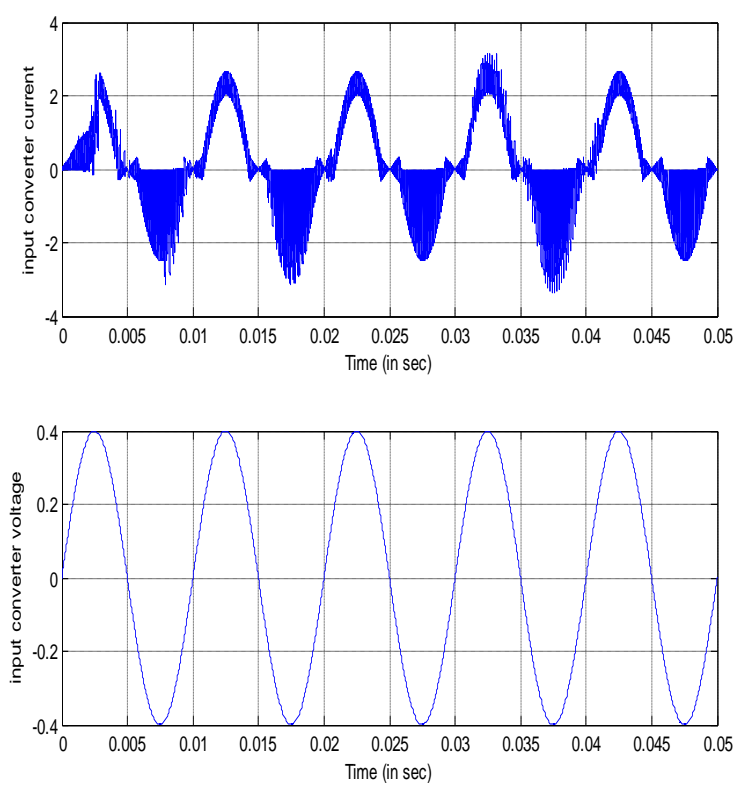

Fig 8 Input current and voltage waveforms for simulation of circuit with feedback
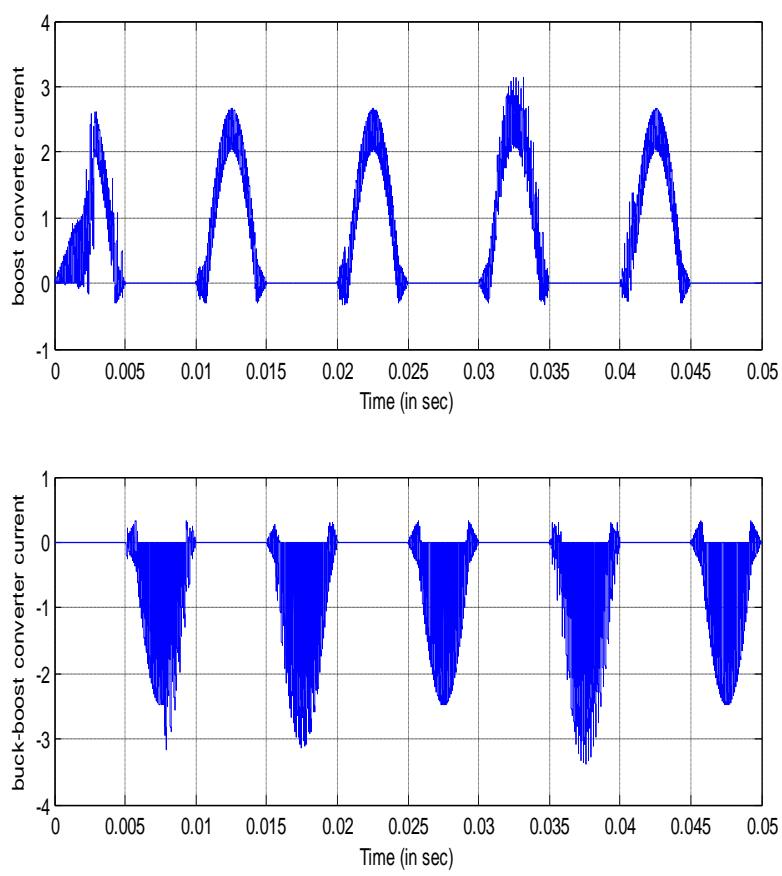

Fig 9 Boost and buck-boost converter currents
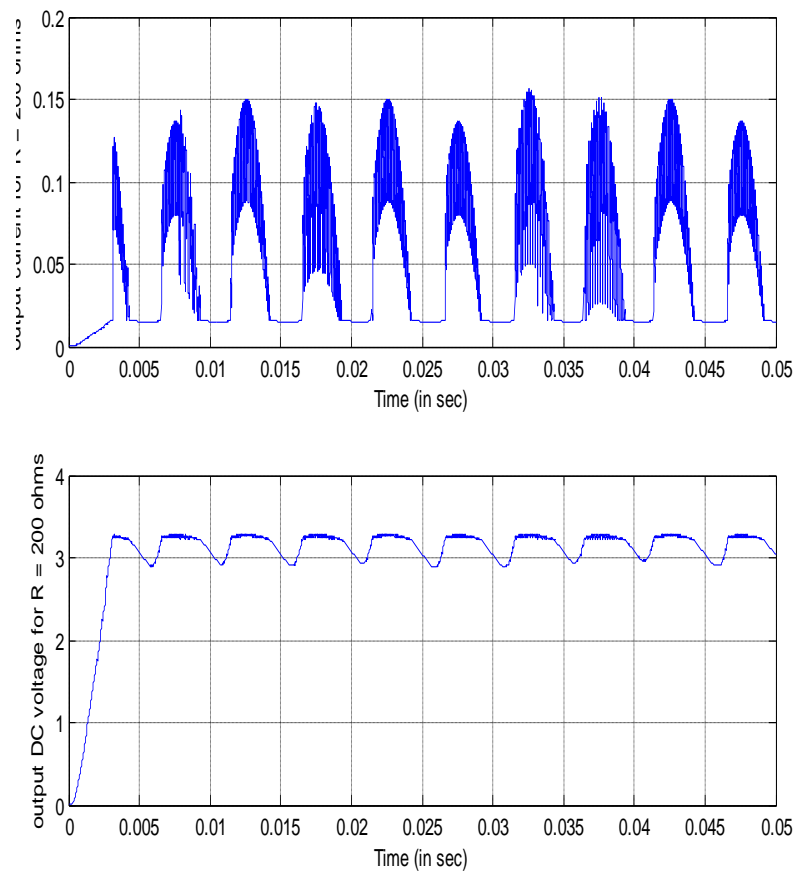

Fig 10 Output current and voltage waveforms for $\mathrm{R}=$ $200 \Omega$

Analysis of the micro-generator and the proposed converter has been carried out to obtain the desirable results. Based on the above, a prototype of the converter has been demonstrated in the MATLAB Simulink software. The efficiency of the converter simulated has been found to be $63 \%$, the voltage ripple about $5 \%$ of the nominal voltage and the power consumption around $55 \mathrm{~mW}$. The converter has been successfully operated to step up the low power voltage in milli volts fed from the AC micro-generator to higher DC voltage to be fed to an electronic load. The loss components have been calculated and presented. The output to input ratio of the converter, 
$\mathrm{Vo} / \mathrm{Vp}$ was found to be equal to 8.25 . Hence, the proposed converter has been successfully implemented.

\section{REFERENCES}

[1] J. A. Paradiso and T. Starner, "Energy scavenging for mobile and wireless electronics," IEEE Pervasive Comput., vol. 4, no. 1, pp. 18-27, Jan./Mar. 2005

[2] S. Dwari, R. Dayal, and L. Parsa, "A novel direct AC/DC converter for efficient low voltage energy harvesting," in Proc. IEEE Ind. Electron. Soc. Annu. Conf., Nov. 2008, pp. 484-488.

[3] P. D. Mitcheson, T. C. Green, E. M. Yeatman, and A. S. Holmes, "Power processing circuits for electromagnetic, electrostatic and piezoelectric inertial energy scavengers," Microsyst. Technol., vol. 13, pp. 1629-1635, May 2007

[4] S. Meninger, J. O. Mur-Miranda, R. Amirtharajah, A. P. Chandrakasan, and J. H. Lang, "Vibration-to-electric energy conversion," IEEE Trans. Very Large Scale Integr. Syst., vol. 9, no. 1, pp. 64-76, Feb. 2001

[5] S. Dwari, R. D. and L. Parsa, "An efficient AC DC step up converter for low voltage energy harvesting," in Proc. Center Power Electron. Syst. (CPES) Semin. Apr. 2007, pp. 452-456.

[6] M. El-Hami, P. Glynne-Jones, N. M. White, M. Hill, S. Beeby, E. James, A. D. Brown, and J. N. Ross, "Design and fabrication of a new vibration based electromechanical power generator," Sens. Actuators A: Phys., vol. 92, pp. 335-342, 2001.

[7] T. M. Thul, S. Dwari, R. D. Lorenz, and L. Parsa, "Energy harvesting and efficient power generation from human activities," in Proc. Center Power Electron. Syst. (CPES) Semin. Apr. 2007, pp. 452-456.

[8] N. G. Stephen, "On energy harvesting from ambient vibration," J. Sound Vibrations, vol. 293, pp. 409-425, 2006.

[9] J. R. Amirtharajah and A. P. Chandrakasan, "Self-powered signal processing using vibration-based power generation," IEEE J. SolidState Circuits, vol. 33, no. 5, pp. 687-695, May 1998.

[10] B. H. Stark, P. D. Mitcheson, M. Peng, T. C. Green, E. Yeatman, and A. S. Holmes, "Converter circuit design, semiconductor device selection and analysis of parasitic for micro power electrostatic generators," IEEE Trans. Power Electron., vol. 21, no. 1, pp. 27-37, Jan. 2006.

[11] C. B. Williams and R. B. Yates, "Analysis of a micro-electric generator for microsystems," in Proc. Int. Conf. Solid-State Sens. Actuators, 1995, pp. 369-372.

[12] P.D.Mitcheson, T. C. Green, E.M.Yeatman, and A. S. Holmes, "Architectures for vibration-driven micro power generators," J. Microelectromech. Syst., vol. 13, no. 3, pp. 429-440, Jun. 2004.

[13] S. Xu, K. D. T. Ngo, T. Nishida, G. B. Chung, and A. Sharma, "Low frequency pulsed resonant converter for energy harvesting," IEEE Trans. Power Electron., vol. 22, no. 1, pp. 63-68, Jan. 2007.

[14] J. Elmes, V. Gaydarzhiev, A.Mensah, K. Rustom, J. Shen, and I. Batarseh, "Maximum energy harvesting control for oscillating energy harvesting systems," in Proc. IEEE Power Electron. Spec. Conf., Jun. 2007, pp. 2792-2798.

[15] S. P. Beeby, R. N. Torah, M. J. Tudor, P. Glynne-Jones, T. O'Donnell, C. R. Saha, and S. Roy, "Micro electromagnetic generator for vibration energy harvesting," J. Micromech. Microeng., vol. 17, pp. 1257-1265, 2007.

[16] T. Paing, J. Shin, R. Zane, and Z. Popovic, "Resistor emulation approach to low-power RF energy harvesting," IEEE Trans. Power Electron., vol. 23, no. 3, pp. 1494-1501, May 2008.

[17] Lefeuvre, D. Audigier, C. Richard, and D. Guyomar, "Buck-boost converter for sensorless power optimization of piezoelectric energy harvester," IEEE Trans. Power Electron., vol. 22, no. 5, pp. 20182025, Sep. 2007.

[18] X. Cao,W.J. Chiang,Y.C.King, and Y.K. Lee, "Electromagnetic energy harvesting circuit with feedforward and feedback DC-DC PWM boost converter for vibration power generator system," IEEE Trans. Power Electron., vol. 22, no. 2, pp. 679-685, Mar. 2007.

[19] K. Ottman, H. F. Hofmann, and G. A. Lesieutre, "Optimized piezoelectric energy harvesting circuit using step-down converter in discontinuous conduction mode," IEEE Trans. Power Electron., vol. 18 , no. 2 , pp. 696- 703, Mar. 2003.

[20] K. Ottman, H. F. Hofmann, A. C. Bhatt, and G. A. Lesieutre, "Adaptive piezoelectric energy harvesting circuit for wireless remote power supply," IEEE Trans. Power Electron., vol. 17, no. 5, pp. 669-676, Sep. 2002.
21] M. Ferrari, V. Ferrari, D. Marioli, and A. Taroni, "Modeling, fabrication and performance measurements of a piezoelectric energy converter for power harvesting in autonomous microsystems," IEEE Trans. Instrum. Meas., vol. 55, no. 6, pp. 2096-2101, Dec. 2006.

[22] Richelli, L. Colalongo, S. Tonoli, and Z.M. Kov'acs-Vajna, "A 0.2-1.2 VDC/DC boost converter for power harvesting applications," IEEE Trans. Power Electron., vol. 24, no. 6, pp. 1541-1546, Jun. 2009.

[23] J. C. Salmon, "Circuit topologies for single-phase voltage-doubler boost rectifiers," IEEE Trans. Power Electron., vol. 8, no. 4, pp. 521-529, Oct. 1993

24] Haslinah Binti Mohd. Nasir, Mai Mariam Binti Mohamed Aminuddin, "Efficient low voltage amplification using self-starting voltage regulator for storage system," in International journal of engineering and technology, vol. 6, no. 5, ISSN 0975-4024, OctNov 2014.

[25] P. D. Mitcheson, T. Sterken, C. He, M. Kiziroglou, E. M. Yeatman and R. Puers, "Electrostatic micro-generators."

[26] M. Ignat, G. Zarnescu, A. L. Catanescu, "Piezoelectric microgenerators for body energy harvesting," in journal of optoelectronics and advanced materials, vol. 13, May 2011.

[27] Y. Rao and D. P. Arnold, Dec.2011 "An input-powered vibrational energy harvesting interface circuit with zero standby power," IEEE Trans.Power Electron. Vol. 26, no. 12, pp. 3524-3533.

[28] S. Roundy, P. K. Wright, and J. Rabaey, July.2003 "A study of low level vibrations as a power source for wireless sensor nodes," Compute.Common, vol. 26, no. 11, pp. 1131-1144.

29] M. R. Sahid, A. H. M. Yatim, Taufik, 2010, "A New AC-DC Converter Using Bridgeless SEPIC”, IEEE, pp.286-290.

[30] C.B.Williams, C. Shearwood, M. A. Harradine, P. H.Mellor, T. S Birch, and R. B. Yates,Jun.2001 "Development of an electromagnetic micro-generator," IEE Proc. Circuits Devices Syst., vol. 148, no. 6, pp. 337-342.

[31] S. Cheng, Y. Jin, Y. Rao, and D. P. Arnold, "An active voltage doubling $\mathrm{AC} / \mathrm{DC}$ converter for low-voltage energy harvesting applications," IEEE Trans. Power Electron., vol. 26, no. 8, pp. 2258-2265, Aug. 2011

32] Anoop D Nath, K. Radhakrishnan, Eldhose. K. A, "Low -voltage direct ac-dc boost converter for micro generator based energy harvesting," International Journal of Advanced Research in Electrical , Electronics and Instrumentation Engineering, vol. 2 issue.3,pp. 1045-1052, Mar.2013.

[33] C. Peters, J. Handwerker, D. Maurath, and Y. Manoli, "A sub-500 $\mathrm{mV}$ highly efficient active rectifier for energy harvesting applications," IEEE Trans. Circuits Syst. I: Reg

[34] S. Cheng, R. Sathe, R. D. Natarajan, and D. P. Arnold,“A voltage multiplying self-powered AC/DC converterwith $0.35-\mathrm{V}$ minimum input voltage for energy harvesting applications," IEEE Trans. Power Electron.,vol. 26, no. 9, pp. 2542-2549, Sep. 2011.

[35] Y.P. Hsieh, J.F. Chen, T.J. Liang, and L. S. Yang, "A novel high step-up dc-dc converter for a micro grid system," IEEE Trans. Power Electron., vol. 26, no. 4, pp. 1127-1136, Apr. 2011

[36] S. Park, Y. Park, S. Choi, W. Choi, and K.-B. Lee, "Soft-switched interleaved boost converters for high step-up and high power applications," IEEE Trans.Power Electron., vol. 26, no. 10, pp. 2906-2914, Oct.2011.

[37] Haoyu Wang, Yichao Tang, Alirezakhaligh, "A bridgeless boost rectifier for low voltage boost rectifier for low voltage energy harvesting applications," IEEETrans. on Power Electron., vol. 28, no. 11, pp. 5206-5214,Nov 2013.

[38] B. Yuan, X. Yang, D. Li, Y. Pei, J. Duan, and J. Zhai,“A currentfed multi resonant converter with low circulating energy and zerocurrent switching for high step-up power conversion," IEEE Trans. Power Electron., vol. 26, no. 6, pp. 1613-1619, Jun. 2011.

[39] S. Dwari and L. Parsa, "An efficient high-step interleaved dc-dc converter with a common active clamp," IEEE Trans.Power Electron., vol. 26, no. 1, pp. 66-78, Jan. 2011

[40] Spiazzi, P. Mattavelli, and A. Costabeber, "High step-up ratio fly back converter with active clamp and voltage multiplier," IEEE Trans. Power Electron., vol. 26, no. 11, pp. 3205-3214, Nov. 2011.

[41] Brigtte hauke, "basic calculation of a boost converter's power stage," application report, SLVA372C, November 2009-revised January 2014 


\section{BIOGRAPHIES}

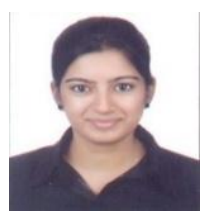

Harshita Bajpai was born in Haryana, India on April 1988. She completed her B. Tech. (Hons) Electrical Engineering in 2010from Rajasthan Technical University, Kota, India. Presently she is a student of M. Tech. (Power Systems)at Rajasthan Technical University, Kota, India. Her research interests include power electronics converters for various applications and renewable energy technology.

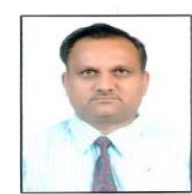

A. K. Sharma was born in Gangapur City, India, in 1962. He received B. E. (Hons.) in Electrical Engineering from $\mathrm{M}$. B. M. Engineering College, Jodhpur, India, in 1986 and M. E. with specialization in Power Apparatus in Electric Drives from University of Roorkee (Presently I. I. T. Roorkee), Roorkee, India in 1993. Presently he is Associate Professor in Department of Electrical Engineering, University College of Engineering, Rajasthan Technical University, Kota, India. $\mathrm{He}$ has published/presented many research papers in International and National Journals/Conferences. He has guided M.E./M.Tech. Dissertations and BE/B.Tech. Projects. His fields of interest include power electronics, electrical machines, electric drives, renewable energy generation, power quality, Flexible AC Transmission Systems, High Voltage Direct Current transmission systems. He is life member of Indian Society of Technical Education (ISTE), Indian Society of Lighting Engineers (ISLE). Fellow member and Chartered Engineer Institution of Engineers (India) (FIE). 